\title{
Why are Older People More Likely to Vote? The Impact of Ageing on Electoral Turnout in Europe
}

\author{
Achim Goerres
}

\begin{abstract}
This article analyses the reasons for higher voting participation among older people in Europe. Over their lifetimes, citizens tend to habituate voting and comply with a growing subjective norm of voting. Furthermore, the average voting participation of older people is influenced by their longer duration of residence, the lack of a mobilising partner, worse physical health and less education, although life experience replaces the function of formal education over a lifetime. Most of these factors are founded on the very nature of human behaviour and the social context of our life course. Thus, they arguably stand outside of the political process and will remain stable into the future.
\end{abstract}

Higher turnout among older age groups, after basic controls for education and gender, has been a consistent finding in many years of research. Older people are more likely to vote-no matter when or where the surveys have been carried out. We are so used to this fact that we forget how unusual the stability of the finding is. Across countries, differences exist in electoral systems, party systems, socioeconomic development and democratic experience. Variations of these country characteristics may have differential impacts on voting participation of various age groups. Over time, there has been a general decline in turnout and a growing disenchantment with electoral politics. In addition to this long-term trend, distinct generations of voters such as the New Deal generation in the USA (Miller and Shanks 1996) or 'Thatcher's Children' in Britain (Russell et al. 1992) have experienced electoral politics in different ways, compared to earlier and later cohorts.

Why is it that older people consistently show a higher propensity to vote despite all these generational changes? This article suggests that older people, compared to younger fellow citizens, have habituated voting over their lifetime and feel a stronger subjective norm to vote. Habituating patterns of social behaviour and complying with social norms are universal human propensities that exist everywhere. There are some further important differences between older and younger voters. Older citizens are on average more likely to vote because they have been living in an area for longer. They are less likely to vote because: (a) they tend to lack a mobilising partner; (b) suffer from worse health; and (c) are less educated as a member of an older cohort, although life experience replaces the function of formal education over a lifetime.

This article analyses international cross-sectional data (the European Social Survey from 2002/3). Countries in the survey vary so much in their political history that older people have experienced a multitude of idiosyncratic national histories. This research design allows the study of common factors such as habituation that accompany the ageing process and are the same in all countries. After a literature 
review, section 1 presents the theoretical conceptualisation of age effects into cohort, life cycle and individual ageing. Section 2 discusses the methods of an age-centred analysis of international cross-sectional data. Section 3 introduces age-related independent variables that we are going to use as proxies for life-cycle and cohort effects. Section 4 shows several series of random-intercept logistic regressions and interprets their results. Section 5 reviews the empirical results in the light of alternative explanations, outlines their wider political implications and shows avenues for further research.

\section{Theory: Age and Political Behaviour}

Imagine meeting two randomly selected citizens in a European country, one of whom is, for example, 70 and the other 40 years old. Can you make any statement about their probabilities of voting participation? Most studies of political behaviour incorporate age as a control variable. The impact of age as a variable is (if at all) discussed only with regards to magnitude vis-à-vis other variables (see, for example, Dalton 2002, ch. 2). This is not very satisfactory because chronological age serves as a surrogate for many other social characteristics that are of importance such as education, health or social connectedness.

Recent discussions of the relationship between age and political participation have concentrated on the contrast between cohort and life-cycle effects in individual countries such as Germany, Canada, Britain or the United States (Miller and Shanks 1996; Becker 2002; Blais et al. 2004; Clarke et al. 2004). These authors detect distinct generational variations within one country. A decline in turnout at Canadian national elections, for example, can be explained by a long-term decline in political attentiveness and civic duty to vote (Blais et al. 2004). The disadvantage of the one-nation approach is the lack of generalisation across more than one nation. This approach can help us to explain differences in turnout between age groups in a given country, but it cannot account for the prevalence of higher turnout among older people in general.

Mark Franklin (2004) explains turnout in established democracies from an internationally comparative point of view. He argues that the fluctuation of aggregate turnout is due to changes in the cohort composition of the electorate. Depending on the socialisation experience at a young age, young voters belong to a group that acquires the habit of voting to a greater or lesser extent than the previous cohort. Besides the emphasis on early socialisation experience, Franklin stresses the habituation process connected to voting to explain higher turnout associated with higher age. However, he does not test this proposition sufficiently. My research takes this last aspect of his argument further.

Voting is the most fundamental form of political participation and can be conceptualised as a decision based on incentives and resources. If citizens do not have certain resources such as physical health, they will not vote. Also, they do not go to the polls if they lack some motivation, such as the belief that it expresses their allegiance to the political system. Resources to go and vote are minimal compared to other forms of political participation (Verba et al. 1995, 53-54); nevertheless some amount of physical ability is needed even for postal voting and some infor- 
mation either from experience or the news in order to decide for whom to vote. In addition, one needs to feel the motivation to pay the small costs in terms of time.

My theoretical perspective includes instrumental as well as expressive motivations. I assume that people vote because they see it as their duty or from loyalty to the system, as well as because they believe that their vote could actually influence policies (see, for a recent review, Dowding 2005). On the one hand, Franklin and his colleagues have shown that institutional restrictions decrease the likelihood of an individual going to the polls so voters must see some kind of instrumental value in the act of voting (Franklin 1996; Franklin et al. 1996). On the other hand, André Blais (2000) demonstrates that rational choice in the narrow sense, in which only personal interests in the political and economic arenas matter, does not hold up.

To what extent can the decision to go and vote based on expressive or instrumental motivation differ between age groups? We can retrace differences between age groups to three types of effects: cohort, life cycle and individual ageing. A 'cohort effect' describes the shared experience by a group that was born during a certain period. There are two sub-types of cohort effects. One is the lasting influence of shared socialisation as a 'political generation'. It matters, for example, in what period a cohort came of political age. We are much more open to political influences between 15 and 30 (the 'impressionable years') than between 50 and 65 (see Hyman 1959; Dawson and Prewitt 1968; Sears and Levy 2003). In Britain, voters who came of political age during the Thatcher or Blair eras seem to bother less about politics, which makes them as a cohort less likely to vote (Clarke et al. 2004). Current British youth do not value formal politics, of which voting forms part, very highly (Henn et al. 2002). In terms of an evaluation of resources and incentives, the incentive side of the equation is affected. The cohort as a whole will carry the perception of a lower benefit value of voting (because of disenchantment with formal politics) through their lifetimes. Although political attitudes like these are not monolithic, they are very stable over a lifespan and will thus make that cohort as a whole less likely to vote in the years to come (Alwin et al. 1991). There are few historical events or processes that can potentially shape generational experiences at a young age across national borders in the realm of voting and create similar lasting influences at later age. Examples might be the experience of the world wars or the fall of communism. However, the experience of the young generation is fundamentally shaped by national circumstances, even if the events were international. This is due to the outspoken national character of parliamentary elections. The issue, candidates and electoral institutional structures that we experience at a young age are the outcome of the national political process.

The second sub-type of cohort effect is the average probability of sharing certain social characteristics as a cohort. Today's elderly have, for example, a lower average level of education as a cohort because mass educational expansion began in most countries in the 1970s. This cohort effect affects our variety and amount of resources to vote. Formal education helps us to understand politics and see the necessity of voting. Other examples are also general changes like de-unionisation or decline in party membership in some countries that make younger cohorts less likely to be mobilised into voting by political organisations. This type of cohort effect 
can qualitatively occur in several countries, but is likely to vary to the extent that two cohorts differ in the distribution of a social characteristic.

'Life-cycle effects' associated with a certain age stem from the insight that our social life course can be separated into different life stages. Each of these stages-youth, adolescence, middle and old age-puts us into social contexts with rather different demands on us as individuals. Globally, there are cultural differences in the social life course for the individual, but, in Europe, the social perception of one's life course is very similar. ${ }^{1}$ Young adults are struggling to succeed in their professional lives, are occupied with starting a family and securing their family's income. Elderly people suffer from deteriorating health, have settled down in a certain area and do not need to support children any more. Changing social circumstances can be reflected in changing political behaviour. The progress through the life cycle does not have a simple increasing or decreasing effect on turnout. Young adulthood might lead a person to take less interest in politics in order to concentrate on beginning a family. Once parents have responsibility for children, they might care more about politics because political output affects not only them, but also their offspring. Voting participation can decrease again with old age because of frailty. Life-cycle effects can affect both sides of the resource-incentive assessment. Resources that enable one to take part in politics, such as available free time, for instance, vary widely over the life cycle. Incentives to vote can also change over the life cycle. Young people who are likely to move soon have a much lower incentive to vote for a local candidate than settled voters.

Life-cycle and cohort effects can also appear in conjunction. Take income, for example. Income is on average lower for all the elderly at all times compared to younger age groups. This is due to the fact that pensions are always below average earnings-a clear life-cycle aspect. But, at the same time, the income of the elderly goes up relative to earlier elderly cohorts because recent retirees have accumulated more wealth and higher pension entitlements during their lives. This allows them to benefit from higher income at old age-a cohort aspect.

The third and, as we shall see, strongest effect can be summarised by 'individual ageing'. As we age, there are two universal human features that increase the likelihood of voting. First, past voting experiences influence the future probability of voting. It is widely acknowledged that the repetition of the same behaviour leads to an increasing probability of performing that behaviour again (see, for a review, Ajzen 2002). If we learn that something brings some kind of gratification to us that outweighs our costs, we will do it again. If something does not give us enough gratification, we will not do it again. Social psychologists disagree to what extent repetitive behaviour is automatic or still influenced by rational consideration. The relatively low frequency of voting (with a maximum of maybe 100 elections per lifetime) compared to other forms of human behaviour suggests that pure environmental cues (such as an election poster) are not enough to generate an automatic response (see Aarts et al. 1998). Instead, we are always required to use some cognitive process to decide whether or not to vote. Nevertheless, voting becomes easier as we get older. Over a lifetime, our repertoire of situations that we know (and also believe we know) grows steadily. The older we are, the more likely we are to 'know the show'. We are constantly confronted with a political environment that 
is too complex for us to deal with (see Lau 2003). Drawing on our own voting experience is one type of cognitive short cut. The easier we find the voting decision, the less costs are involved in going to the polls. ${ }^{2}$

But why do we decide to vote again? The infinitesimally small contribution of our vote does not get larger by having voted once. We could instead come to the conclusion that voting does not matter and learn from our voting experience not to vote again. Here, the second feature of the individual ageing effect comes in: the older we are, the more likely we are to adhere to the social norm of voting. ${ }^{3}$ Voting is a socially desirable behaviour in liberal democracies. Even in recently established democracies, most citizens go to the polls in national elections. In addition, most people (even if they have not voted) maintain that we ought to vote (see Blais 2000). Thus, the norm of voting (a) can be observed by seeing people going to the booth or reading about turnout figures in the media; and (b) is a moral rule that brings social gratification for the voter. ${ }^{4}$

The transmission process between a social norm and our individual behaviour is complex. A social norm affects us differently depending on our social context. At the level of the individual, we are motivated to behave in a certain way by our own subjective norm. The subjective norm is our perception of the social norm in our personal environment. This subjective norm is the sum of social pressure and gratification that we expect to receive from people who we know (Fishbein and Ajzen 1975; Ajzen and Fishbein 1980; Ajzen 1991). Since voting is a widespread social norm in a liberal democracy, many people are likely to subscribe to the view that we ought to vote. As we age, the more we become part of a society through widening social networks, interactions and social role taking, the higher the number of people is in our environment whom we believe to hold that view. As we get older, we can count more people who we think might want us to vote. This is, of course, a probabilistic statement. It is possible to live in a social context where few people vote, so that one cannot see anyone go to the booth or feel social gratification by voting and then talking about it (although one would still be exposed to the voting norm in the media). However, as we age, we are unlikely to feel increasing social pressure not to vote. Non-voters do not care about voting. They do not usually maintain that we ought not to vote. In other words, getting older in such a social context implies getting to know a growing number of people who do not care about voting and some people who do maintain that voting is desirable. Thus, over a lifetime, the subjective norm to vote increases even in these extreme circumstances because the non-voters in this environment will not affect our subjective norm, whereas the few voters will. ${ }^{5}$

In sum, the older we are, the stronger is our subjective norm to vote and the less costly the voting decision because of our own past voting experience. This individual ageing effect should exist regardless of any country context. It is founded on universal human features such as the tendency to comply with social norms and to use past experience as a cognitive short cut.

\section{Methods}

The discussion so far has stressed that differences between age groups are determined by effects that differ in their level of universality: country-specific effects 
(political generation, average probability of sharing certain social characteristics), life-cycle effects that are the same in Europe and the universal individual ageing effect. As I have shown in the literature review, conventional techniques commonly used to study age effects, such as the analysis of pooled cross-sectional data, do not allow generalisations beyond the country studied. Furthermore, researchers employing them face the 'identification problem' (see Glenn 1976) (for example, a cohort effect can be an ageing effect interacting with a period effect).

To test the proposed age effects and their different levels of universality, I suggest studying an international, cross-sectional survey, i.e. samples were only taken at one point in time but in several countries. The European Social Survey covers 21 European countries that are similar in their cultural perception of the social life course and dissimilar in their political history. The experience of a 70-year-old in Poland is very different from a 70-year-old in Britain with regard to political history, such as the fall of communism, but similar as to social roles associated with the life cycle such as retirement, grandparenthood or deteriorating health. If we take a primary interest in age effects that are more universal and depend less on national circumstances, we can use the diversity of countries to isolate these more general effects. ${ }^{6}$ In a cross-sectional data set, we are faced with confounded age-cohortperiod effects. However, with a comprehensive international survey such as the European Social Survey that includes many questions about the social background of respondents, we can test hypothesised life-cycle and cohort effects by looking at conceptual variables. We can, for example, model life-cycle variation in incentives by looking at how long someone has been living in a certain area because we know that the older you are, the longer you have lived in a certain place and the higher your incentive to vote will be. Thus, we can control for age effects at the individual level.

Life-cycle and individual ageing effects are hypothesised to be more universal than political generation effects. Political generation effects are likely to be country specific and cannot be totally captured by survey items. We will first pool all data from 21 countries (as diverse as Poland, Greece, Sweden or Austria) and control at the individual level for all life-cycle effects, cohort effects that give cohorts different probabilities of attaining a certain social characteristic and part of the political generation effect (such as the expressed sense of duty to vote). Now we are left with a residual chronological age variable that still represents individual ageing and political generation effects. However, we can hypothesise that the political generation effects cancel each other out in the pooled analysis. This is due to the diversity of countries. The ageing effect is tinged by differences in cohort socialisation in country A, but these cohort differences will not occur in country B where others are present that do not occur in country A.

In the pooled analysis, the residual age variable should show a monotonous increasing concave relationship because habituation and norm-conforming processes are likely to show declining rates of growth. Our early experiences of voting will have a stronger impact of future voting opportunities than later ones. Also, our subjective norm is likely to grow most in early adulthood, when we experience most changes in our social environment. In separate single-country analyses, the relationship between residual age and voting participation is tinged by cohort 
Figure 1: Different Types of Age Effects, Their Level of Universality and Empirical Procedure for Analysis

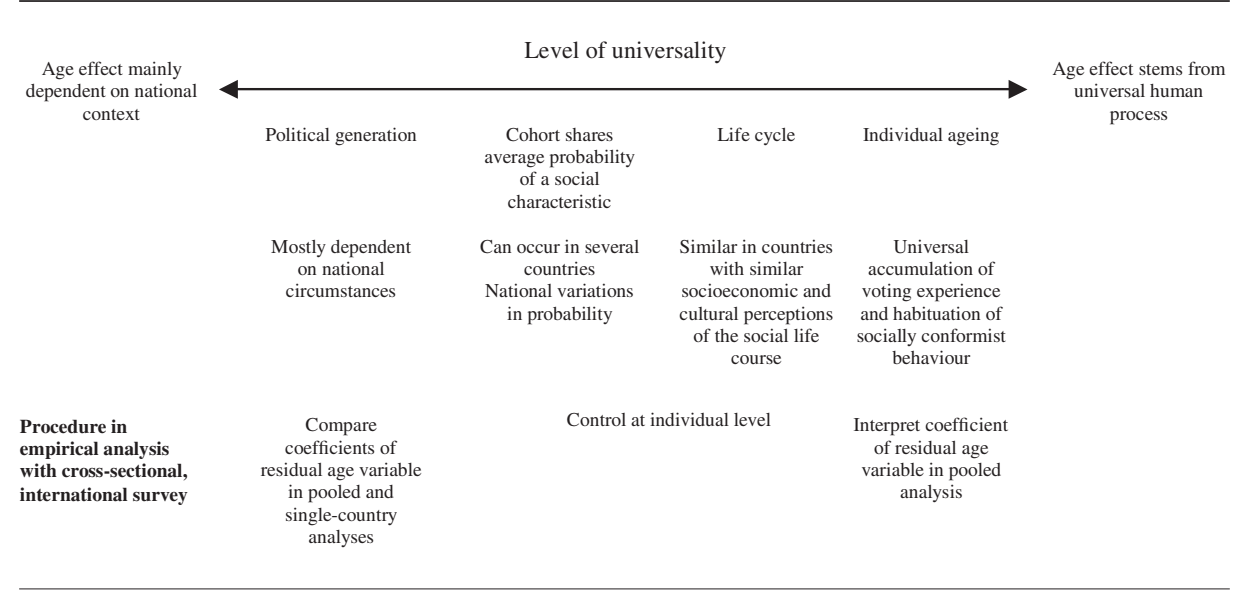

differences in socialisation experiences. Thus, the appearance of a concave relationship between residual age and turnout in the pooled analysis of diverse countries lends support to the hypothesis that we habituate socially conformist behaviour over our lifetimes. Figure 1 summarises the conceptual considerations about age effects and methodological implications.

The approach has two limitations. Firstly, we are not able to study political generation effects in detail. This does not mean that we assume them to be nonexistent, but pooling all data serves to overcome the idiosyncratic national cohort effects and to filter out more universal effects. In this analysis, we cannot say, for instance for Britain, how large the individual ageing effect is vis-à-vis British political generation effects. However, since we are able to control for many differences between generations, the residual effects that we cannot account for are probably rather small. Its relative impact in each country must be inferred from further analysis of other longitudinal data sets. Secondly, we cannot model interaction effects between period and cohort or period and life-cycle effects. Period effects cannot be modelled at all because all respondents in one country are exposed to the same period effect. Therefore, any interaction term between age groups and period cannot be traced. Thus, the implicit assumption of such an analysis is that period effects do not interact with life-cycle or cohort effects. However, period effects are likely to be shaped by national circumstances. If they do interact with any agerelated effects, it is fair to assume that they will do so in each country, rather than in the pooled analysis.

\section{Independent Variables}

We assume that a voter decides (not) to vote after a consideration of costs and benefits that includes instrumental as well as expressive motivations. We further 
Table 1: Age-related Independent Variables, Pearson's r

\begin{tabular}{lcc} 
Independent variables & $\begin{array}{c}\text { Overall correlation } \\
\text { with age }\end{array}$ & $\begin{array}{c}\text { Expected correlation } \\
\text { with voting } \\
\text { participation }\end{array}$ \\
\hline Cohort effects & $0.20^{* *}$ & + \\
Religiosity & $-0.18^{* *}$ & + \\
Education & & $+16^{* *}$ \\
Cohort/life-cycle effects & $0.15^{* *}$ & + \\
Party identification & $-0.13^{* *}$ & + \\
Sense of duty to vote & $0.08^{* *}$ & + \\
Income & $0.03^{* *}$ & + \\
Political interest & $\mathrm{N} / \mathrm{a}$ & + \\
Trade union and party membership & & - \\
Gender (female) & $0.67^{* *}$ & + \\
Life-cycle effects & $0.54^{* *}$ & + \\
Pension main source of income & $-0.47^{* *}$ & + \\
Duration of residence & $-0.36^{* *}$ & + \\
Number of minor children in household & + \\
Subjective evaluation of health & $-0.26^{* *}$ & + \\
Living with partner & $-0.09^{*}$ & + \\
Friends in non-political networks & $-0.08^{* *}$ & + \\
Internal political efficacy & $-0.07^{* *}$ & + \\
External political efficacy & & + \\
\hline
\end{tabular}

* Significant at $0.05 ;{ }^{* *}$ significant at 0.01 one-tailed, weighted by design weight, coding in the appendix

${ }^{\dagger}$ These variables have a curvilinear relationship with age, correlations are for respondents 40 years and older

conceptualise age effects on voting participation as political generation, a shared cohort probability of attaining a certain social characteristic, life cycle and individual ageing. In line with the methodological approach, we need to control for life-cycle and cohort effects that are not political-generation effects level with a series of conceptual variables. In order to decide which variables we should include, we must ask: (a) where cohorts differ in their cost-benefit calculation of voting; and (b) how transitions over the life cycle affect the calculation. Although technically unnecessary, we furthermore typify the variables according to the cohort/life-cycle differentiation for ease of interpretation. ${ }^{7}$

Table 1 lists the range of independent variables. According to the literature, two are pure cohort and seven are pure life-cycle effects. For six variables, there is a mixed expectation. As a first empirical test, each variable has been tested as to whether it has the expected bivariate correlation with age. ${ }^{8}$ I will now discuss groups of independent variables in detail, starting with those that have a suppressing effect on turnout for older people. A variable has a suppressing effect either because it is negatively related with age and positively with turnout (such as education) or the other way round (such as health). 


\subsection{Suppressing Turnout}

Education, income: the so-called 'standard model' of political participation postulates that higher socioeconomic status has a positive impact on participation. Higher education enables citizens to have a better understanding of politics (for an overview, see Leighly 1995). At the same time, they are more likely-because of occupation and income-to be in a social context where norms of participation prevail. Higher-income citizens also have a higher material stake in the system. The spread of mass education, however, is a relatively recent phenomenon, so there is a clear generational decline in aggregate levels of education. Income declines with age, mirroring cohort and life-cycle differences. Older generations do earn less, but all the elderly have less income as they retire.

Gender: entrenched understandings of traditional gender roles could interact with age since newer cohorts are less likely to hold them. Also, it is necessary to include gender because older age groups are comprised of more women on the grounds of their longer life expectancy.

Living with a partner, number of minor children in household, subjective evaluation of health: these are clear life-cycle effects. To live together with a partner increases the chance of voting because the partner is another potential mobilising source. On the grounds of widowhood and divorce, this is negatively correlated with age for people who are 40 and older. Children enhance one's personal interest in public provision. A certain amount of physical fitness is needed to undertake even the minimal requirements of voting. Frailty increases with age (Gehring and Wagner 1999, 696-697). ${ }^{9}$

Friends in non-political networks: probably the most influential work of social gerontology puts forward the 'disengagement thesis' (Cumming and Henry 1961). The elderly are thought to show a decline in interpersonal activity as they disengage themselves from their social environment. This disengagement includes the political sphere, so that levels of participation should drop. The retreat should be reflected in a decline in the number of social networks that are reported to include close friends. The social retreat would then not only affect the political sphere directly, but also decrease the possibility of being mobilised in a non-political context, such as by friends. Social networks are considered to be important in making people participate in politics in general (Knoke 1990). The disengagement thesis has been tested numerous times with mixed results, so its exclusion is not warranted (Gergen and Back 1966; Glenn and Grimes 1968; Glenn 1969; Rollenhagen 1982).

Internal and external political efficacy: one strand of the social gerontological literature deals with problems of ageism in western societies (see, for example, Wilson 2000, 161-162). Negative stereotypes of inactivity in the elderly reflect back on senior citizens and determine their self-image in a way that may make them feel less politically efficacious. As a result, internal and external political efficacies decrease, so that the political participation of older people is hampered.

Trade union and party membership: membership in a political organisation is a strong mobilising factor in voting because members are exposed to the activists' efforts to 
make them cast their vote favourably to the organisation. Some countries have experienced a decline in party and trade union membership, which would be reflected in ageing membership profiles (Widfeldt 1995). Retirement leads to exit from trade unions in some countries.

\subsection{Boosting Turnout}

Sense of duty to vote: in the survey, respondents have been asked to give an answer to the following question on an 11-point scale: 'To be a good citizen, how important would you say it is for a person to vote in elections?' This variable is helpful to catch some of the variation in individually felt subjective norms. According to our theoretical expectations of norm habituation over a lifetime, we can expect this item to show the features of a life-cycle effect. Unfortunately, we must expect over-reporting of such a socially desirable trait, so the proxy loses its power. In addition, the decline of the sense of duty to vote as a cohort effect has been established in several country studies (Blais et al. 2004; Clarke et al. 2004).

Religiosity: secularisation makes newer cohorts less religious. Religiosity seems to increase our felt obligation to comply with social norms.

Duration of residence: this is considered to be one aspect of social connectedness. The longer you have been living in a certain area, the more likely you are to be socially settled so that you can pay attention to the increasingly familiar problems of that area that might need political solutions (Miller and Shanks 1996, 100-106). ${ }^{10}$

Party identification: research into the decline of institutional forms of political participation holds that younger generations identify less with parties than with other political groupings with a smaller scope of activity. On the other hand, the older a person is, the higher the potential attachment to their party as they have more time to grow attached, which could explain the higher level of party identification for older people (Converse 1976; Butler and Stokes 1983, 59-61; Fuchs and Klingemann 1995; Tilley 2003).

Pension as a main source of income: to be dependent on pensions could be a mobilising factor because politics can be important in determining the source of income (see Campbell 2003).

Political interest: the disengagement thesis would hypothesise a decrease in political interest. But, a competing hypothesis of 'selective withdrawal' would demand that politics might be one of the few areas where the elderly decide to remain active. This view predicts a general social retreat among the elderly accompanied by the concentration on fewer subjects, including politics (Glenn and Grimes 1968). Political interest is thereby a strong predictor of political participation because it decreases information costs. Citizens who are politically interested do not view obtaining information about politics as a costly necessity, but draw some enjoyment from it. Younger cohorts, for example in Britain, show less interest in formal politics (Henn et al. 2002).

The following empirical investigation will show that not all of these variables are equally important when considered in a multivariate analysis. I will show that the 
pure life-cycle effects of having lived in an area for longer, lacking a cohabiting, mobilising partner and deteriorating health are those factors that have the strongest impact on an older person's likelihood to vote.

\section{Results}

The empirical analysis can be divided into three different steps. Firstly, I want to establish the relative impact of the enumerated independent variables in multivariate models (Table 2, models 1-3). Secondly, I will demonstrate the universal presence of individual ageing by comparing the results of the pooled analysis with results from separate country regressions (Figure 2). Thirdly, I will run several tests with sub-samples (Table 3) showing that: (a) the impact of the individual-level variables does not vary a great deal depending on the macro country context (models 4a-c); (b) differences between age groups are greater in low-turnout countries; and (c) the causal mechanism behind the effect of individual ageing on voting participation is the habituation of socially conformist behaviour (models $5 a-b)$.

I am using random-intercept logistic regression models for the analysis of several countries at the same time. We know from the analysis of electoral institutions that they affect the average probability of the eligible voter to go to the polls. By modelling a random intercept as part of these models, I allow this average probability to vary between countries. The dependent variable is a dichotomy of whether the respondent voted in the last national parliamentary election or not.

Table 2 shows a series of three regressions. Model 1 only has age dummies as explanatory variables as a reference model. Model 2 includes the full list of independent variables. There are some age-related effects that lose significance in the multivariate model: religiosity, income, social networks, external political efficacy and pension as the main source of income. Model 3 introduces an interaction term between education and age. The final column in Table 2 shows the difference in fitted probabilities between the minimum of the independent variable and the maximum when other effects are being held constant in model 3. However, these calculations do not tell us enough about the differences between age groups because the model looks at all variance within as well as between age groups.

Figure 2 illustrates which variables are most important to explain the differences between age groups. The horizontal axis shows the absolute value of the bivariate correlation of the independent variables with age. The vertical axis shows the impact as calculated by the difference in fitted probabilities. From this age-centred perspective, the variables that stand out as having a relatively high impact, as well as a stronger correlation with age, are the following: duration of residence, if someone is living with a partner, number of minor children in household and subjective evaluation of health. However, none of these is as strong as the residual age variable, which would be higher on the vertical and more to the right on the horizontal axis than any of the control variables.

There are some remarkable aspects about these four factors. For one, all of them are purely sociological and stand outside of the political process. It is the social context 


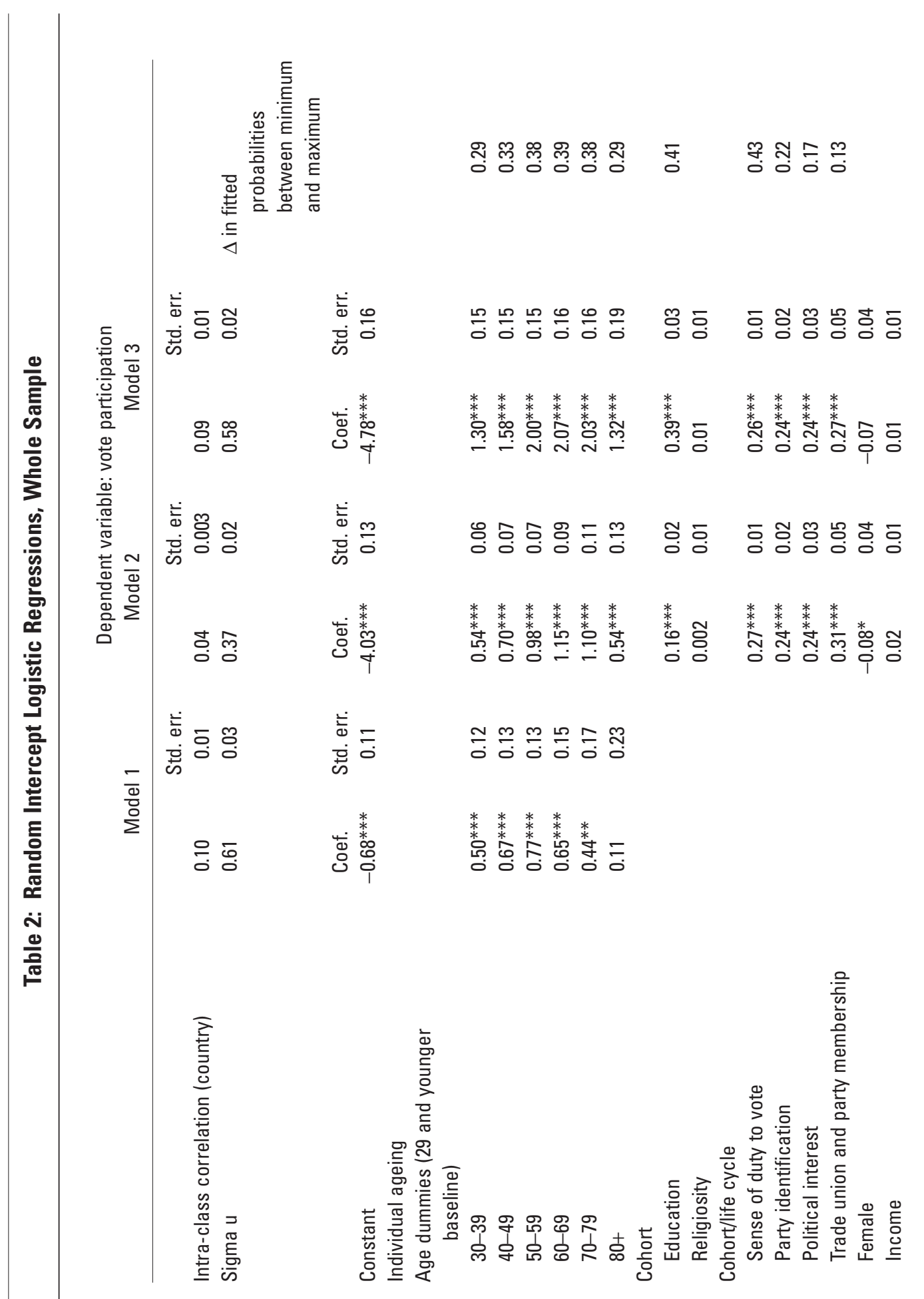




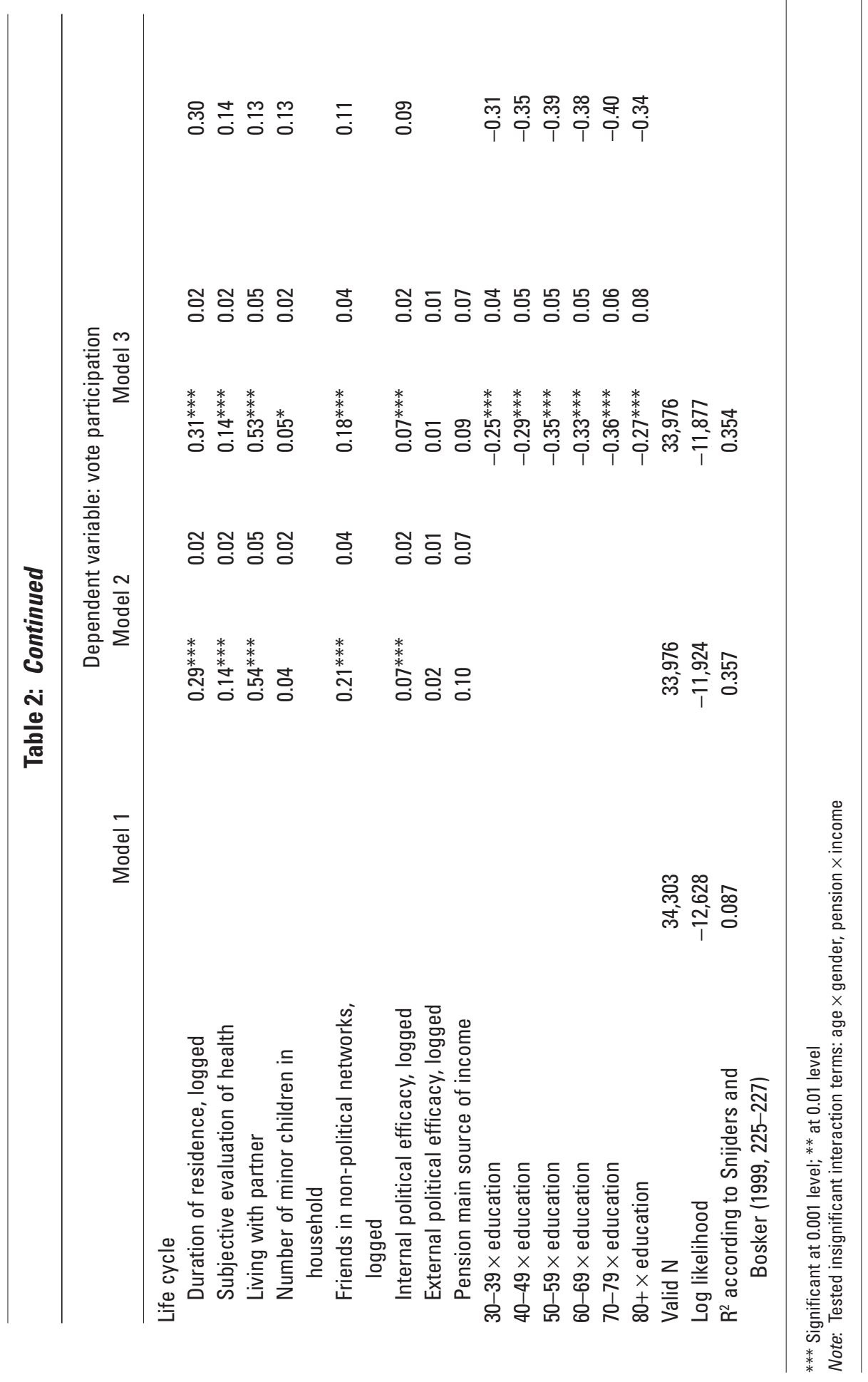


Figure 2: The Impact of Age-related Independent Variables and Their Correlation with Age

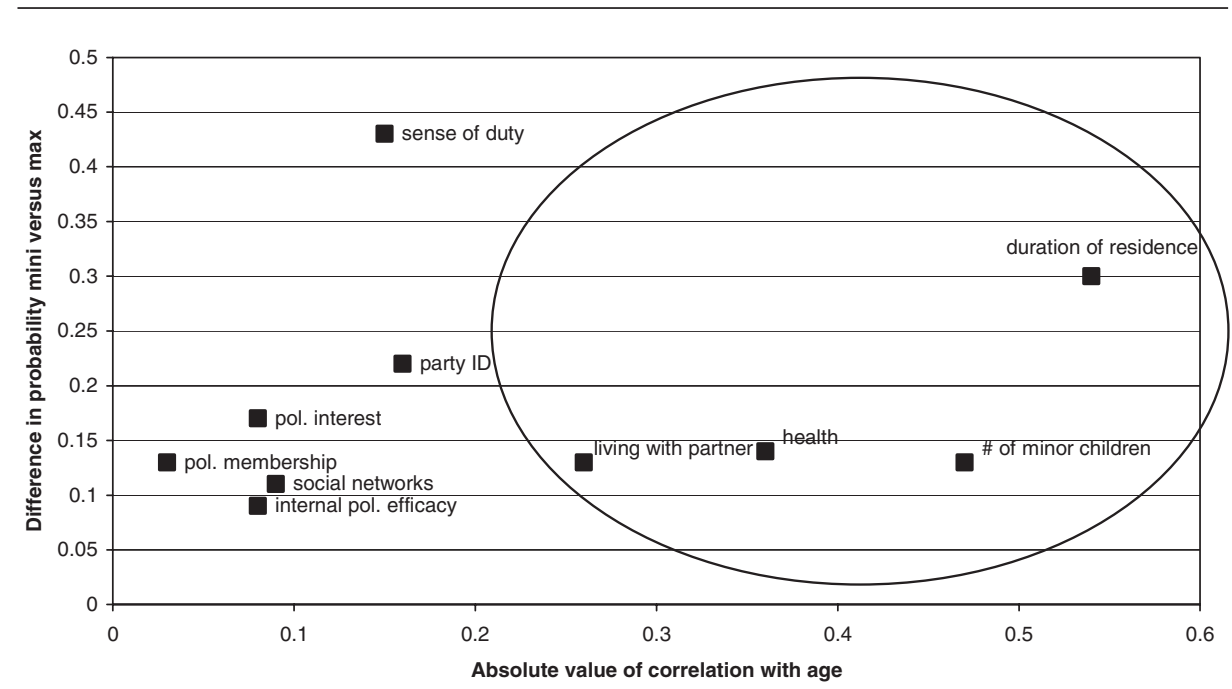

Note: Living with partner and number of minor children for respondents aged 40 and older.

that matters rather than the political to explain variation between age groups. All of these variables describe life-cycle effects. The probability of living with a partner and having minor children increases from youth to middle age and decreases thereafter. Duration of residence (health status) increases (decreases) linearly with age. Secondly, the impact of these factors on voting participation is arguably quite stable since they are embedded in a cultural conception of a social life course that is only subject to slow societal change. Finally, three of the four most important age-related effects make elderly people less likely to vote, which shows the large impact of the other positive effects, namely individual ageing and the duration of residence.

Model 3 in Table 2 further introduces an interaction effect between education and age. This was first shown by Wolfinger and Rosenstone (1980) with US census data and confirmed by Rosenstone and Hansen (1993) with US election surveys. ${ }^{11}$ The older the voters are, the smaller the gap is between different educational groups. Highly educated citizens generally show a higher likelihood of voting because they are more likely to understand the political process and live in a social context where norms of participation prevail. Over a lifetime, however, less-educated people catch up with their more-educated fellow citizens of the same age. This can be explained by the substituting effect of life experience for education. The learning effect through own past experience is stronger for people of lower educational backgrounds over a lifetime.

Let us now turn to the interpretation of the general curvilinear increase of voting participation in all educational groups if plotted against age. Figure 3 shows the results of 21 regressions, one per country (based on model 2). The horizontal axis shows the fitted probability for all other variables held constant except for age. As we can see, there is a lot of variation between countries. ${ }^{12}$ Most countries do show 
Figure 3: Variation between Age Groups as to Fitted Voting Probability, Analysis for Each Country Separately and for Pooled Sample

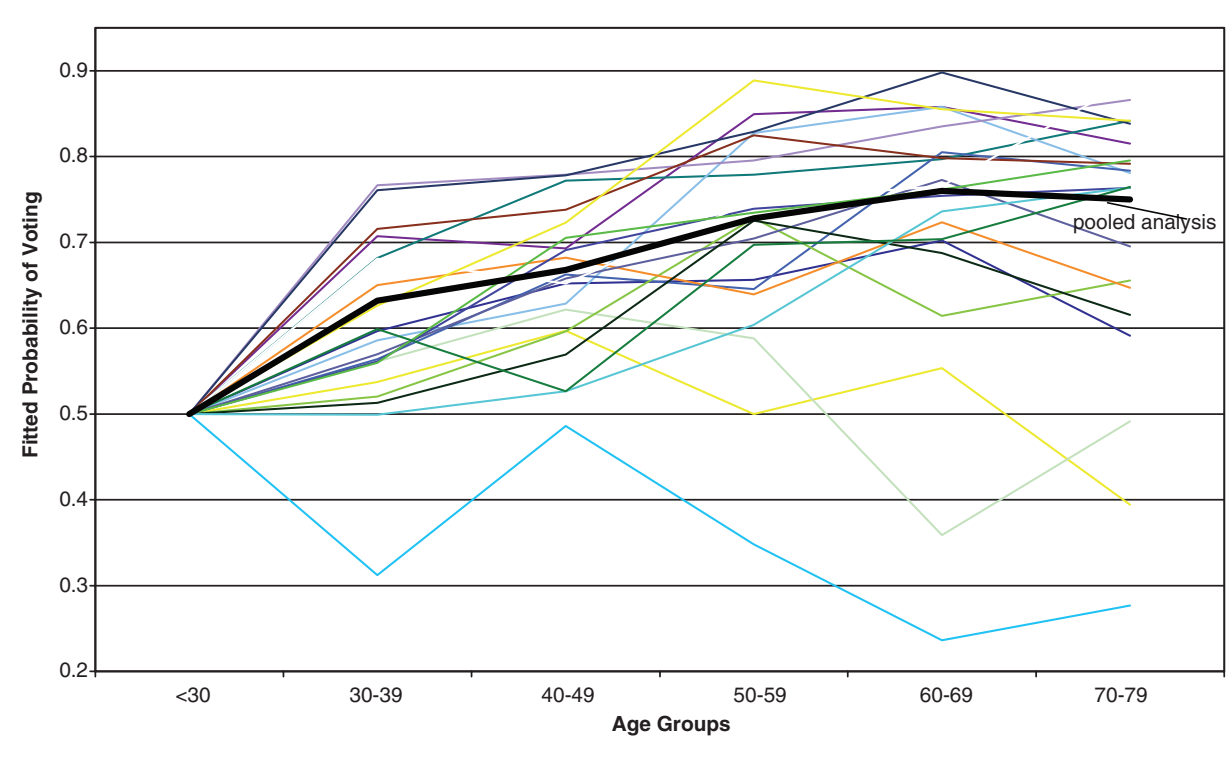

an increasing tendency with age, but not all. The reason for the difference between countries lies in the cross-sectional nature of the data. If we look at, for example, the British 50-59-year-olds and their likelihood of voting, this average probability is not only determined by individual ageing but by the cohort experience of those who have been born between 1942 and 1952. We can control for part of this cohort experience, namely the shared probability of attaining a social characteristic such as education or religiosity, at the individual level. What we cannot control is the shared experience as a political generation that might make this age group different from others in Britain. However, these political generation effects are determined by national political history. Therefore, the graphs of each country look very different. If we pool all respondents into one analysis, these political generation experiences cancel each other out. In the pooled analysis, they become a kind of white noise that does not affect the universal experience that all countries share: individual ageing. The thick concave line represents the result from the pooled analysis. As hypothesised, we see a clear increasing trend at decreasing rates. This is the typical form of a learning curve. I hypothesise that the causal mechanism behind this individual ageing effect is the habituation of socially conformist behaviour. To lend evidence to this, we can split the sample in two different ways for two series of regressions as a second test.

The first division separates the countries according to their average parliamentary turnout 1945-2001 (according to IDEA 2005, 83-84). ${ }^{13}$ The first group of low-turnout countries consists of France, Hungary, Ireland, Luxembourg, Poland, Switzerland and the United Kingdom (51.4 per cent-74.9 per cent). The medium-turnout countries are Finland, Germany, Greece, Norway, Spain, Slovenia 


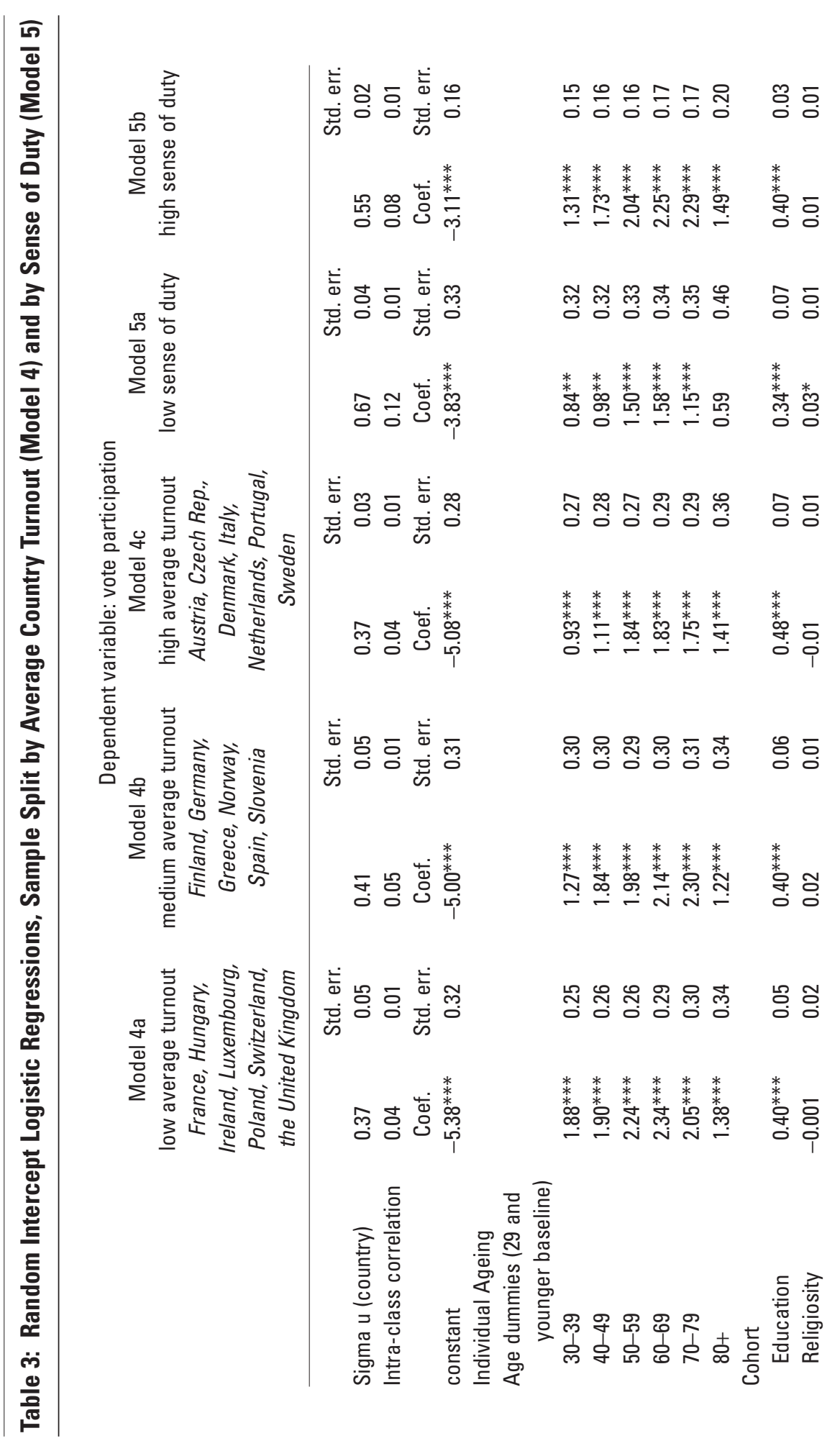




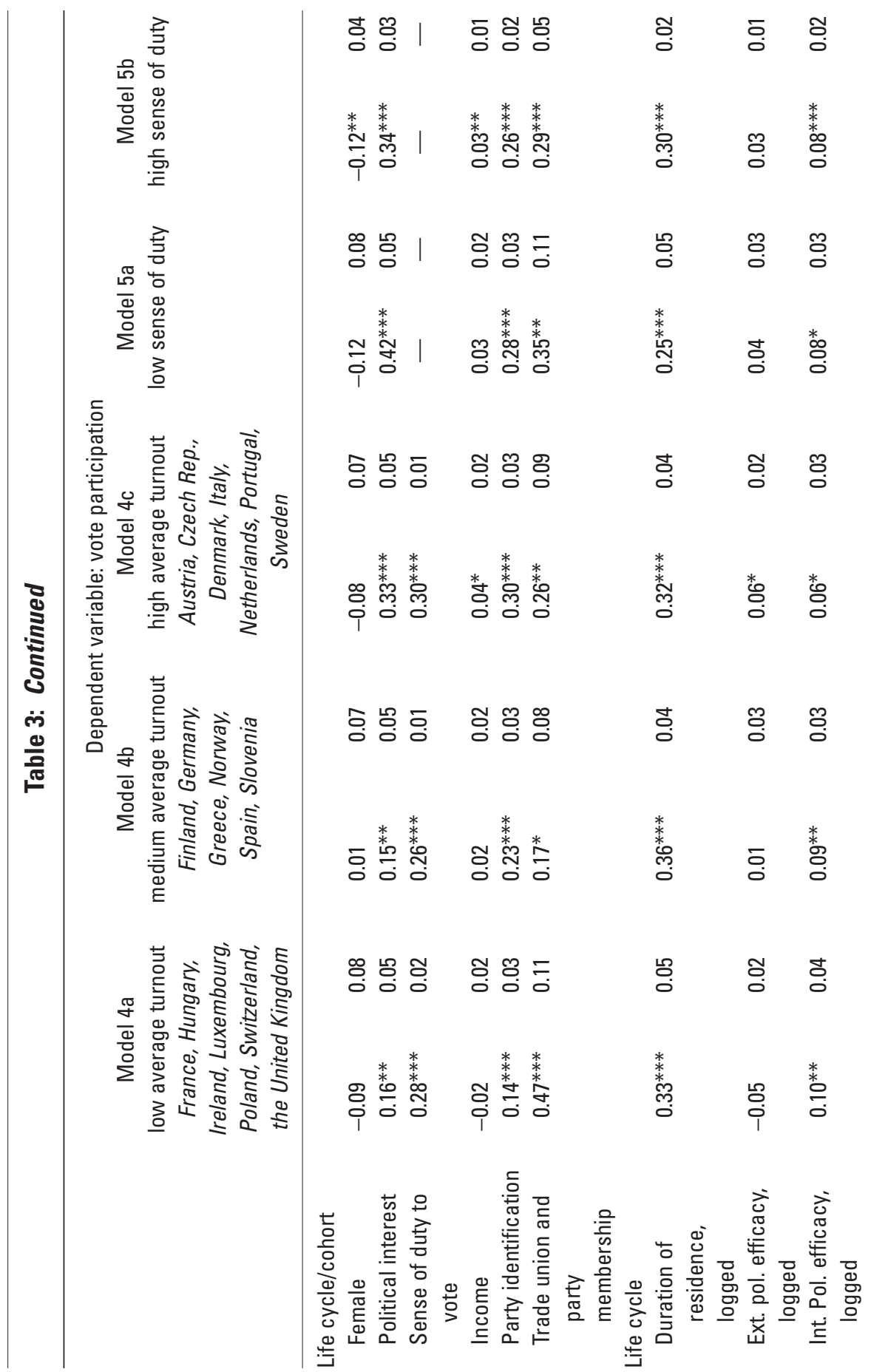




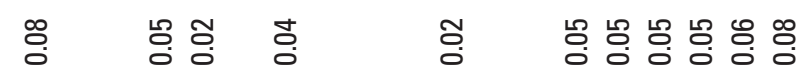

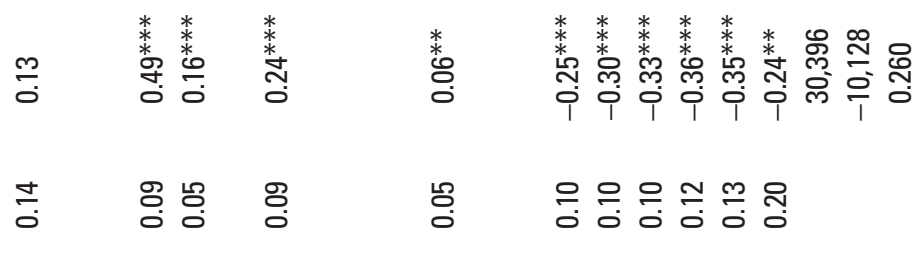

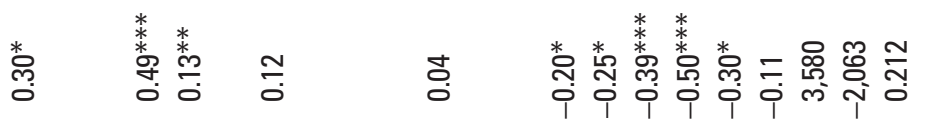

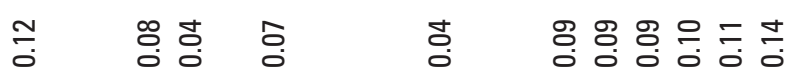

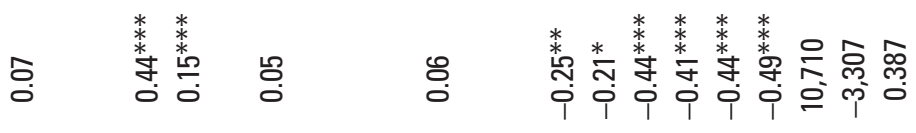

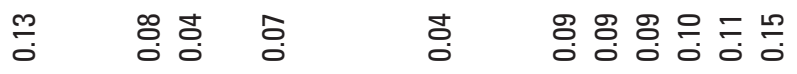

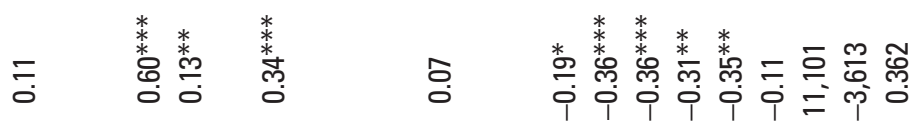

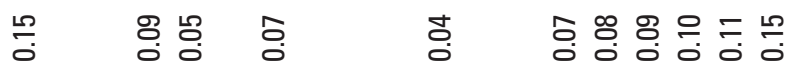

然 $\quad$ 类兑

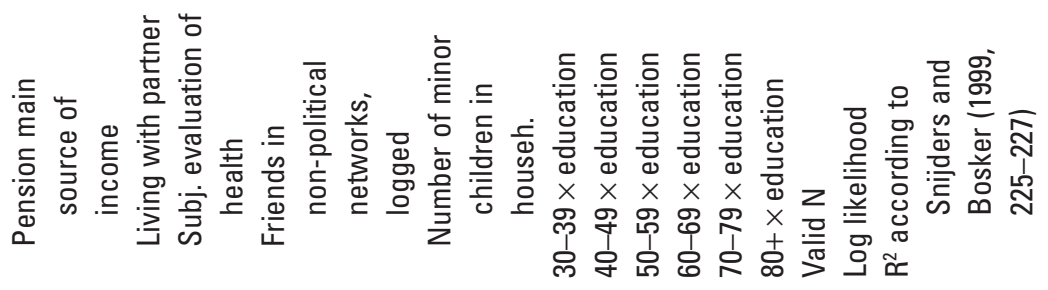


(76.4 per cent-80.8 per cent). The final group of high-turnout countries consists of Austria, Czech Republic, Denmark, Italy, Netherlands, Portugal and Sweden (83.8 per cent-92.0 per cent). Belgium has been excluded from the last group because of its system of compulsory voting with strong enforcement that leads to high turnout. The size of each sub-sample is between 10,700 and 11,000. Higher average turnout is relevant in two ways. First of all, the norm of voting is more established in that country since more people practise it. Secondly, comparative research suggests that turnout is higher when elections are held in a way in which the voter perceives a stronger instrumental incentive to vote (Franklin et al. 1996).

Table 3 shows the regressions (models $4 \mathrm{a}-\mathrm{c}$ ). Some of the small-impact coefficients change significance somewhat. That should not concern us too much because their minor impact makes them more interesting as control rather than substantive variables. It is important to note that no coefficient changes its sign. ${ }^{14}$ Three out of the four social characteristics that are so important in explaining variation between age groups (duration of residence, health, living with partner) show stable coefficients. Number of children becomes insignificant in all three models. That shows us that this is not a good proxy, because we cannot be sure about the direction of its impact. All other coefficients with strong impacts remain quite similar. Party identification changes its coefficient depending on the country group. It becomes twice as high in the high-turnout states in comparison to those with low turnout. This is not due to sampling error, which is relatively small for this independent variable. It could be that party identification is a stronger mobilising factor in countries in which perceived costs of voting are lower (higher-turnout countries).

If we now turn to the coefficients of the age dummies, we can see that the overall curvilinear relationship is the same. The interaction terms with education remain quite similar. However, compared to younger age groups, older age groups are the more likely to go to the polls, the lower the average turnout in that country. If you compare the coefficients line by line, you can see that they decrease from left to right in all instances except for the medium group in the 80-plus category. Thus, an older citizen differs from a younger one, all other things being equal, more in a country like Britain or Poland (low turnout) than in Denmark or Austria (high turnout). This can be explained by the fact that in a country with low turnout, there is less social pressure to conform for all age groups. Thus, a young person in those countries feels less incentive to conform to the voting norm. Over a lifetime, however, a person learns to conform more and more as they become part of a social context which values that norm. Starting from a lower level at a younger age, there is more room for the habituating process towards the top. Highly educated people start from a higher level and the habituation process is less pronounced. In countries with low average turnout, new voters start with a lower incentive to conform to the norm and there is more room for habituation.

Another test for the nature of the habituation process is to split the sample into two groups according to their reported sense of duty to vote. The group with a low sense of duty is those respondents with a score $0-4$, the group with a high sense of duty is those with a score $5-10 .{ }^{15}$ The sample with the lower sense of duty consists of about 3,600 respondents; the other of about 30,400. Naturally, standard errors are about half the size in the larger sample compared to the smaller. In general, for 
those with a low sense of duty the coefficients of the explanatory variables are equal or a bit higher than in the group with the higher sense. This can be explained by the fact that mobilising or de-mobilising factors have a stronger impact on those who feel a lower civic duty to vote.

Figure 4 shows the relationship between age, education and the fitted probability of voting, all other things being equal for the two sub-groups. Not surprisingly, those who feel a high sense of duty have a higher probability of voting in general, compared to their counterparts of the same age and educational background. If we now look at Figure $4 \mathrm{a}$ for those with a high sense of duty, there is no variation between age groups and the probability is close to 100 per cent. This is the graphic embodiment of the ceiling of habituation. Those who feel a high sense of duty at a young age have a high incentive to vote when they are also more highly educated, which gives voters an understanding of the political process. Thus, life experience cannot lead to more habituation in this group of voters because they are likely to vote in every election. For those with low educational backgrounds and a high sense of duty, life experience substitutes for understanding the political process by education. Figure $4 \mathrm{~b}$, in contrast, paints a different picture for those with a low sense of duty. Here, high educational background does not equate with high participation. The relationship across age groups is positive and does not look similar to the individual ageing effect. This stems from the fact that those people who are highly educated and thus prone to have a greater understanding of the political process do not habituate voting across their lifetime because they do not perceive it as a civic duty. Thus, it would be inconsistent for them to conform to a kind of behaviour that they do not deem desirable. For those with low educational backgrounds, there is still some residual effect of life experience teaching them the norm. It might be that the less educated are more open to social pressure because they are not cognitively mobilised to resist the habituation of a norm they do not agree with. All in all, this habituation pattern is much less pronounced, however, in comparison to the other patterns we have seen.

\section{Conclusions}

This article has shown that non-political factors are most important in explaining the higher turnout of older voters, factors that lie in the social context of our life cycle and the human nature of habituation and seeking to conform. The most significant factor comes from individual ageing through which voters habituate the socially conformist behaviour of voting. Life experience can further teach the importance of voting in such a way that it acts as a substitute for education. Individual ageing does not vary between countries with different turnout levels. Additional factors of importance for senior citizens are longer residence in one place, the growing likelihood of lacking a mobilising partner and deteriorating health.

Are there any alternative explanations for the increasing voting probability of ageing voters? Possibly, the older we are, the more we have at stake in a political system. In that case, it would not be social norms that drive us, but personal material interest. The older we are, the more we possess and the more dependent 
Figure 4: (a) Variation between Age Groups as to Fitted Voting Probability, High Sense of Duty to Vote. (b) Variation between Age Groups as to Fitted Voting Probability, Low Sense of Duty to Vote

a

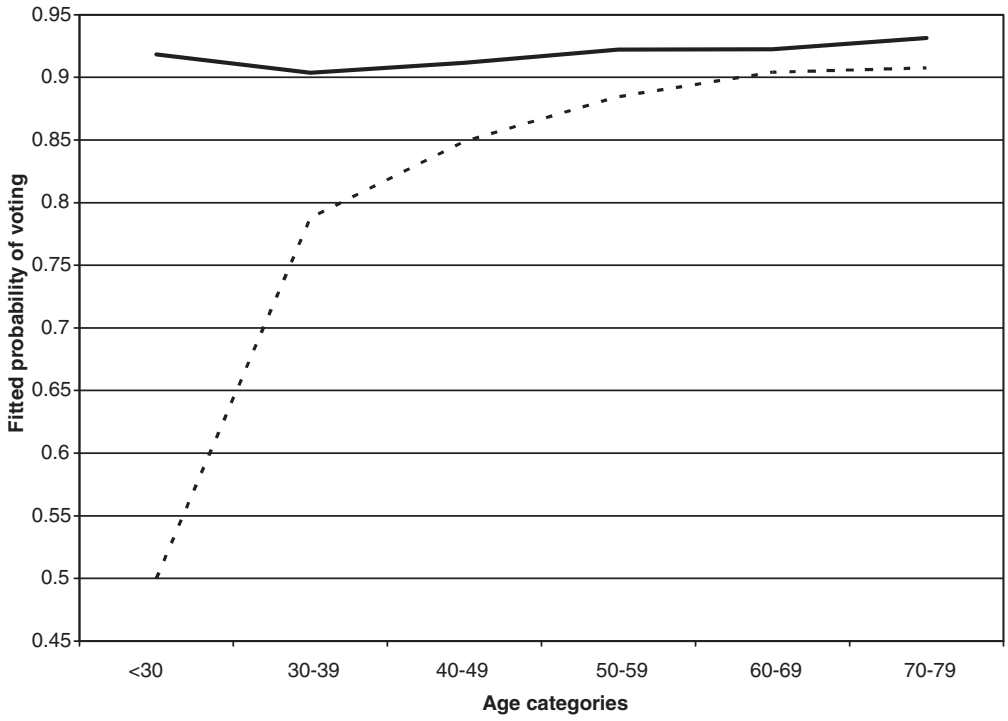

- - - low education - high education

b

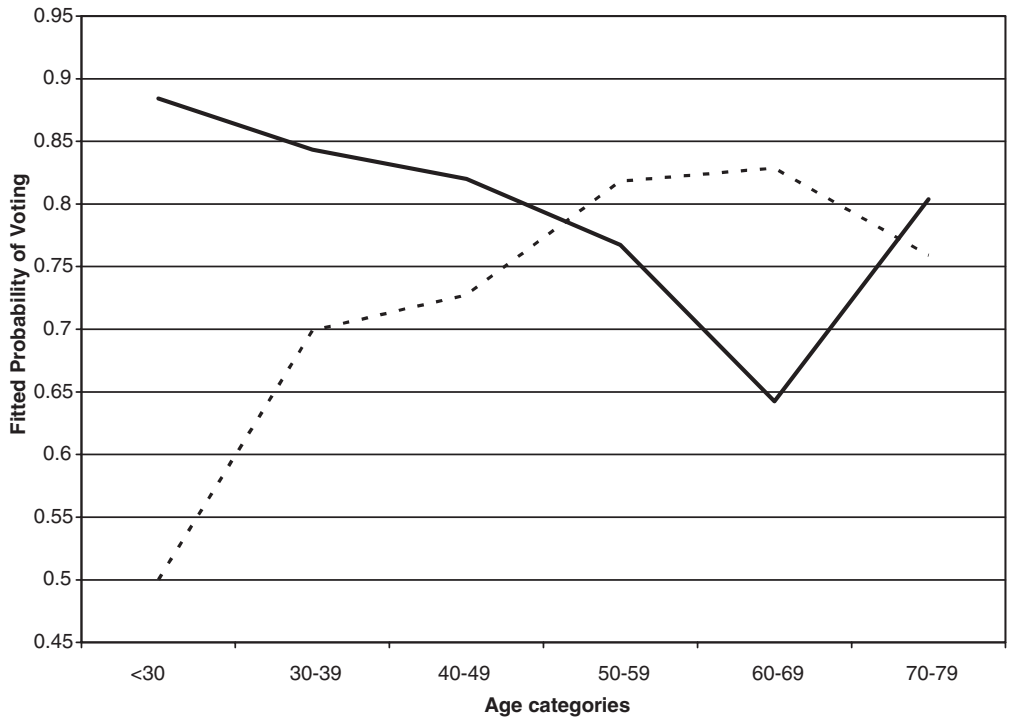

on (or used to) public provision we become. Thus, we would lose more if we did not exert our right to vote. This explanation is implausible because our vote contributes infinitesimally little to the outcome. If this explanation were true, the differences between countries would not be the way they are. Economic interests that grow 
alongside ageing should not depend on the average turnout of the country. Thus, the systematic pattern that age differences are largest in low-turnout countries would remain unexplained. Also, direct measures of material interest such as income and pension income would not be insignificant.

Another hypothesis could attribute the rise in turnout with age to an allencompassing generational difference in acknowledging voting as an important function of democracy. This notion is equally shared by older people and equally less shared by younger persons (because they might see other forms of participation as more effective). This explanation is highly unlikely. Why should the elderly in Ireland share the same sense of usefulness in voting as older Poles? Both groups have lived through very different experiences of democracy. Therefore, finding an all-overriding generational effect in so many countries is improbable.

The causal explanation of habituation derives further evidence from a recent experimental study (Gerber et al. 2003). Voters are influenced by their own past political behaviour. If a person is mobilised to go and vote in one election, he or she will have a higher likelihood of going to the polls in the next election. This increased probability of voting manifests itself despite a lack of mobilisation at the second vote. If we accept my explanation, we can also draw some conclusions for the wider political process. The higher turnout among older voters lies in non-political causes. They cannot easily be influenced by policy-makers because they have their roots in the social framework of our life cycles and in our human nature. Thus, if European democracies maintain the overall attitude that voting is fundamental to democracy, older people will continue to go to the polls more regularly than younger people. In democracies that show growing numbers of older people, we can thus expect an expanding over-representation of older voters in national elections.

In the last British general election, Age Concern England was campaigning on behalf of older voters (see their web site www.20millionvotes.org.uk). They invited MPs from all parties to public discussions of old-age issues and invited older people to write to their candidates. Age Concern did not recommend voting for any party, but their campaign was threatening because it demonstrated the massive electoral power of the grey vote. Whether the vote of older people makes a difference is another issue because they do not tend to vote for one party only. But, the combination of demographic weight and high voting probability that goes beyond class and education makes Age Concern's threat credible.

Further research should be carried out with qualitative methods to obtain a second layer of analysis in addition to the multi-N, quantitative approach used here. New research should concentrate on two things. (1) In-depth interviews with young, middle-aged and older people should focus on single steps in the causal chain that makes voters comply with the social norm of voting. (2) Comparisons should be made across countries to make qualitative judgements about similarities and differences among older voters in new versus established democracies, especially looking into the relationship between political experience in a communist regime and its impact on subsequent political behaviour in a liberal democracy.

\section{About the Author}

Achim Goerres, Government Department, London School of Economics and Political Science, WC2A 2AE, UK, email: A.Goerres@lse.ac.uk 


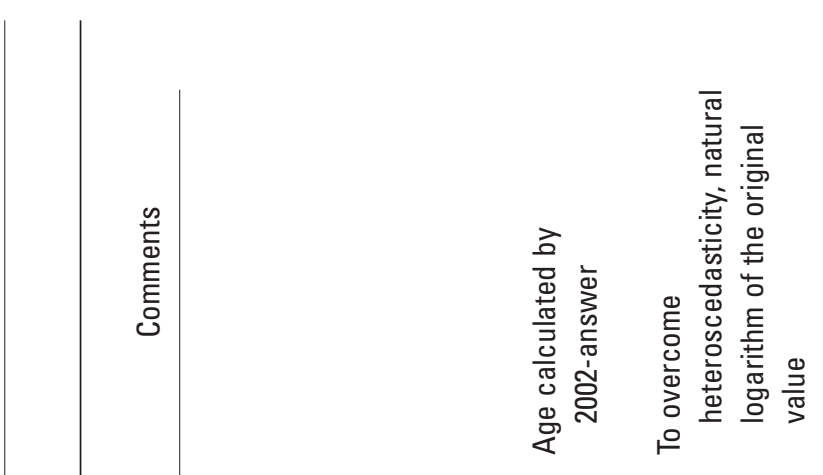

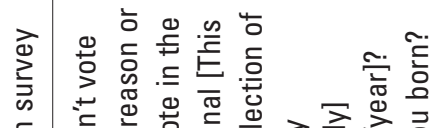

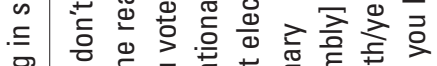

官

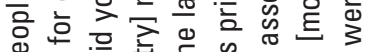

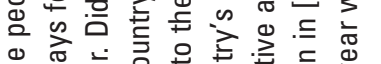

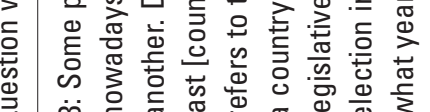

i்

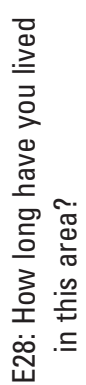

范

क 它

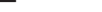

$\stackrel{\infty}{\infty}$

$\sum_{\substack{\mathbb{D} \\ \infty}}^{\infty} \underset{0}{\infty}$

尺

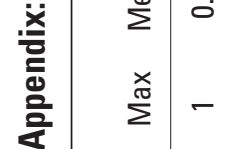

กั่

$\infty \quad \infty$

$\stackrel{5}{\Sigma} 0$

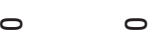

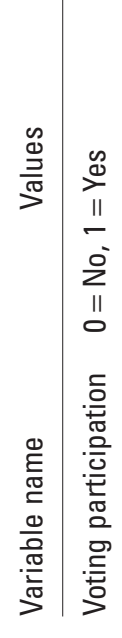
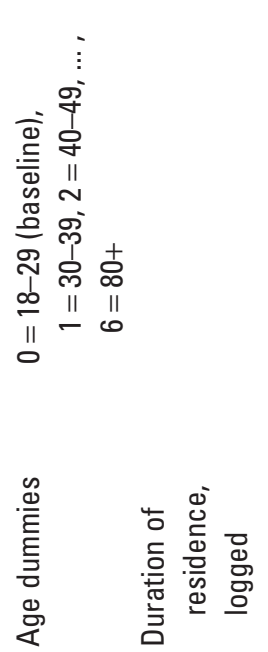

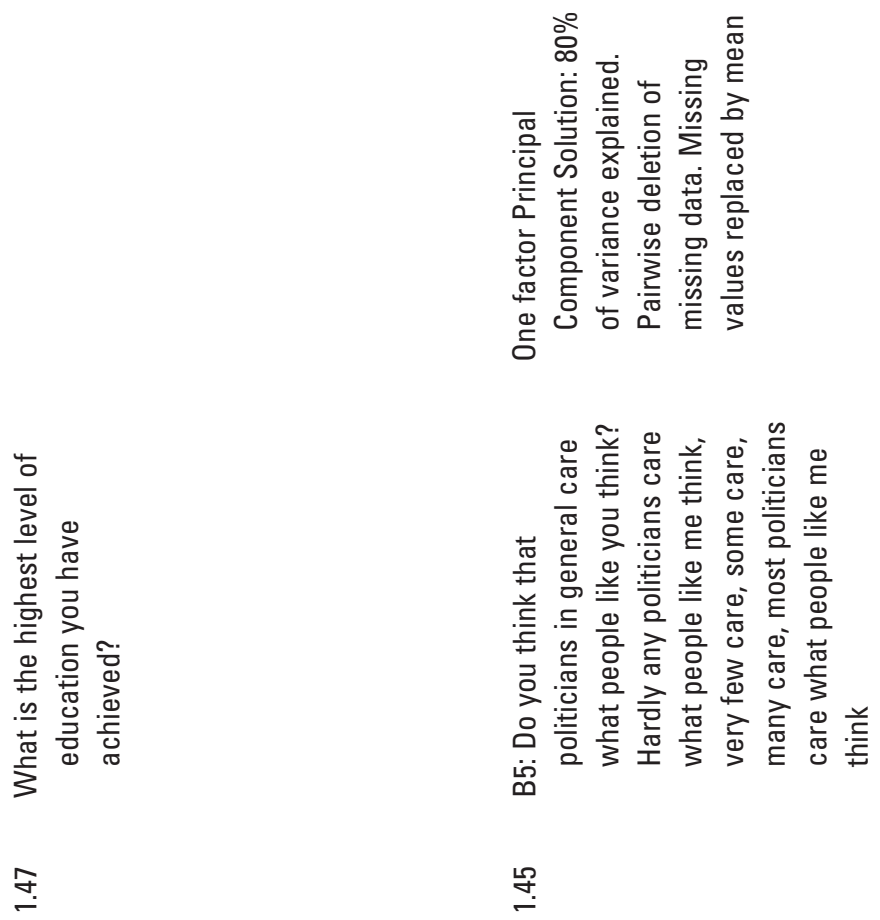

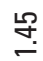

$\stackrel{\infty}{\infty}$

$\stackrel{\infty}{-}$
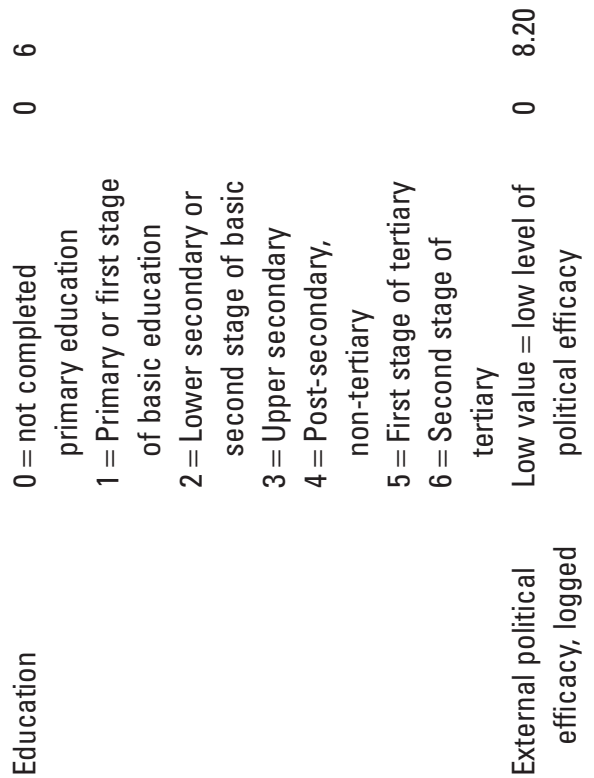


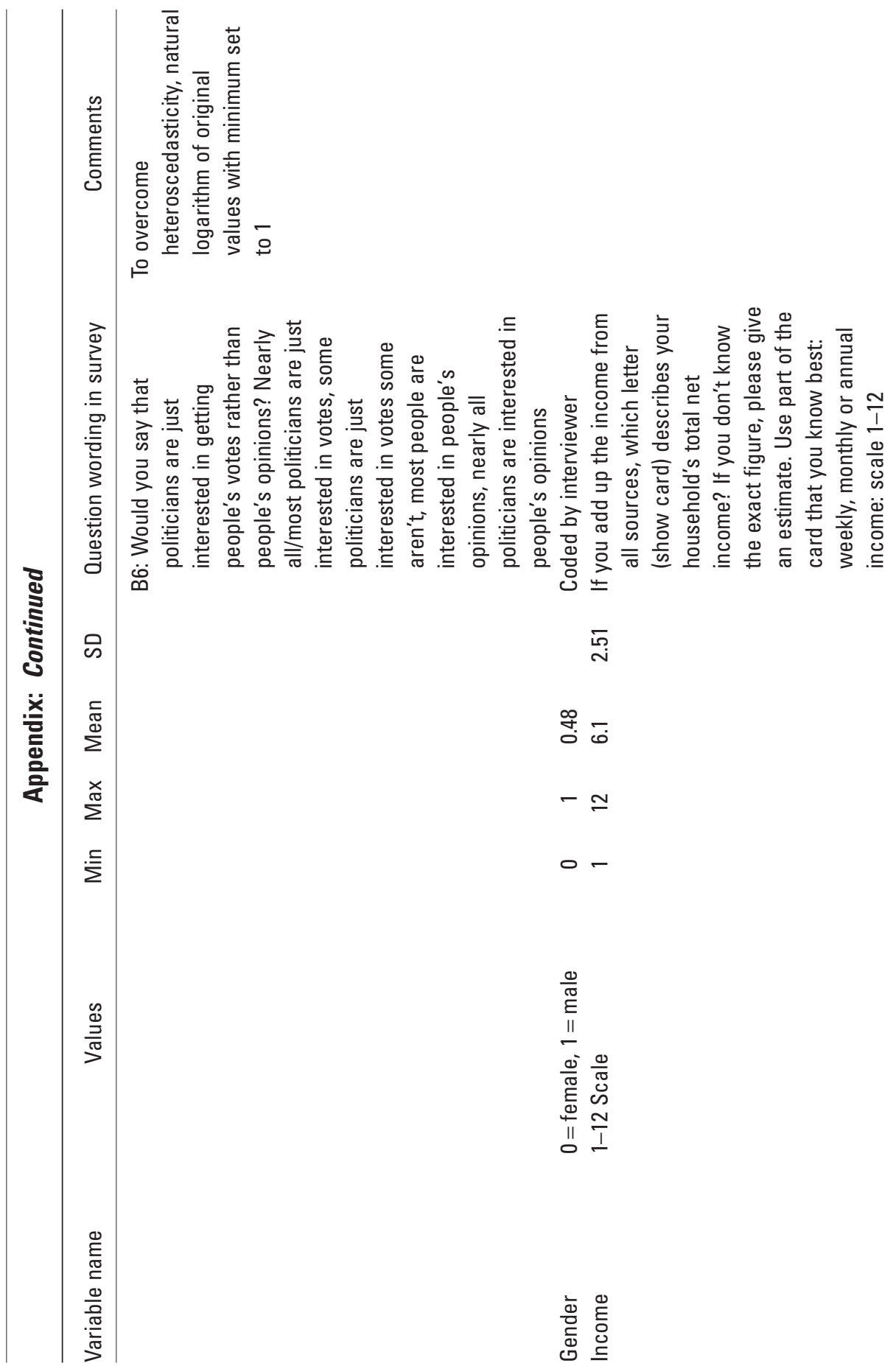



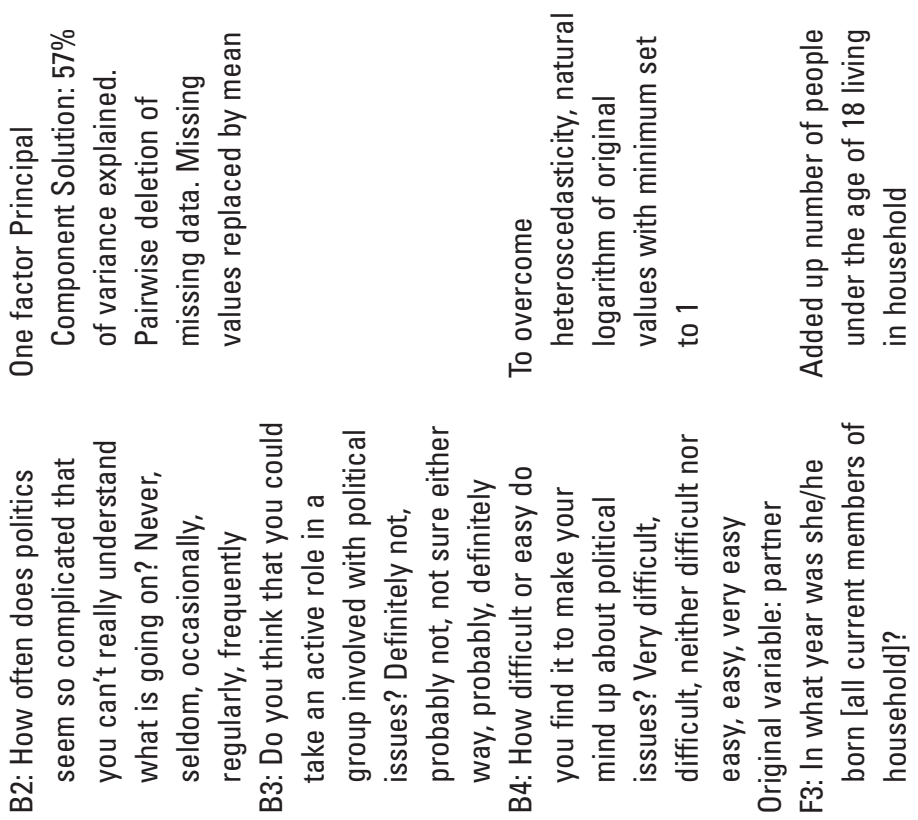

$\stackrel{0}{=}$

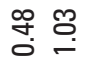

๓ึ

茴

$\underset{\substack{\infty \\ \&}}{\infty}$

-으

$\circ$

$\circ 0$

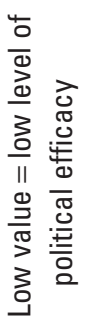

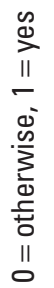
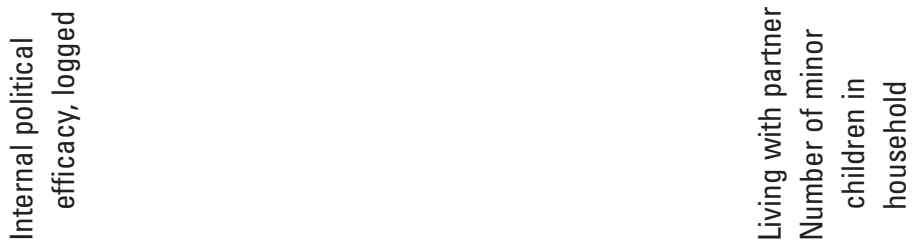


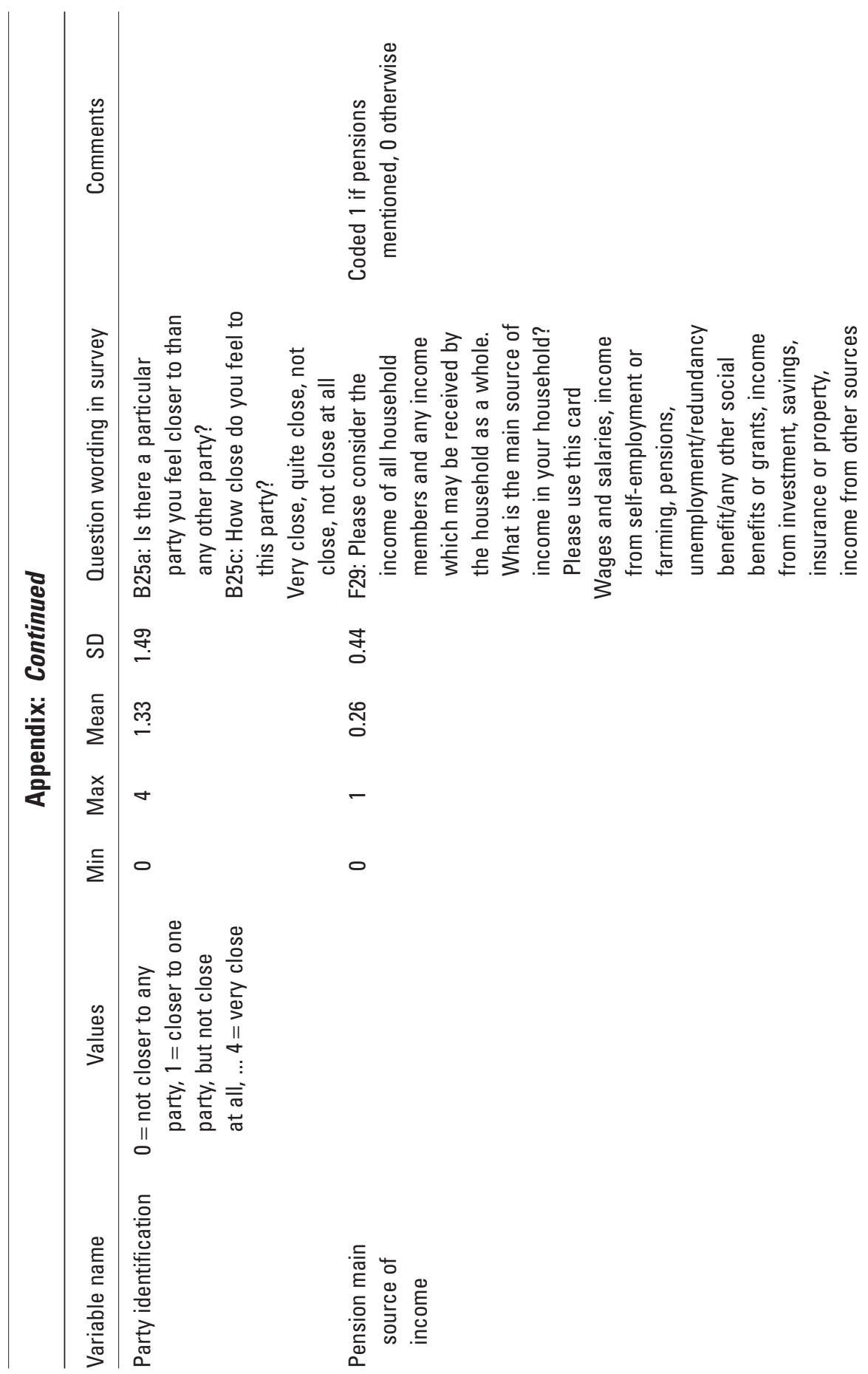



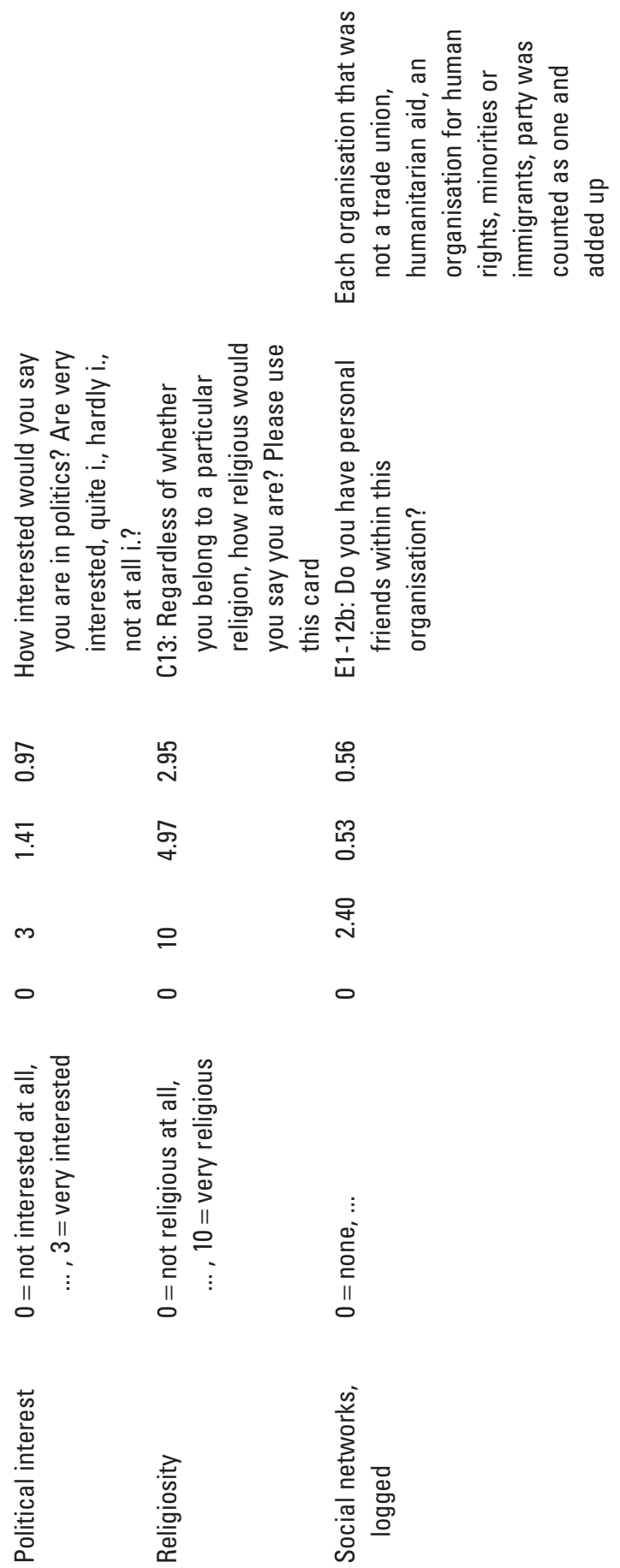


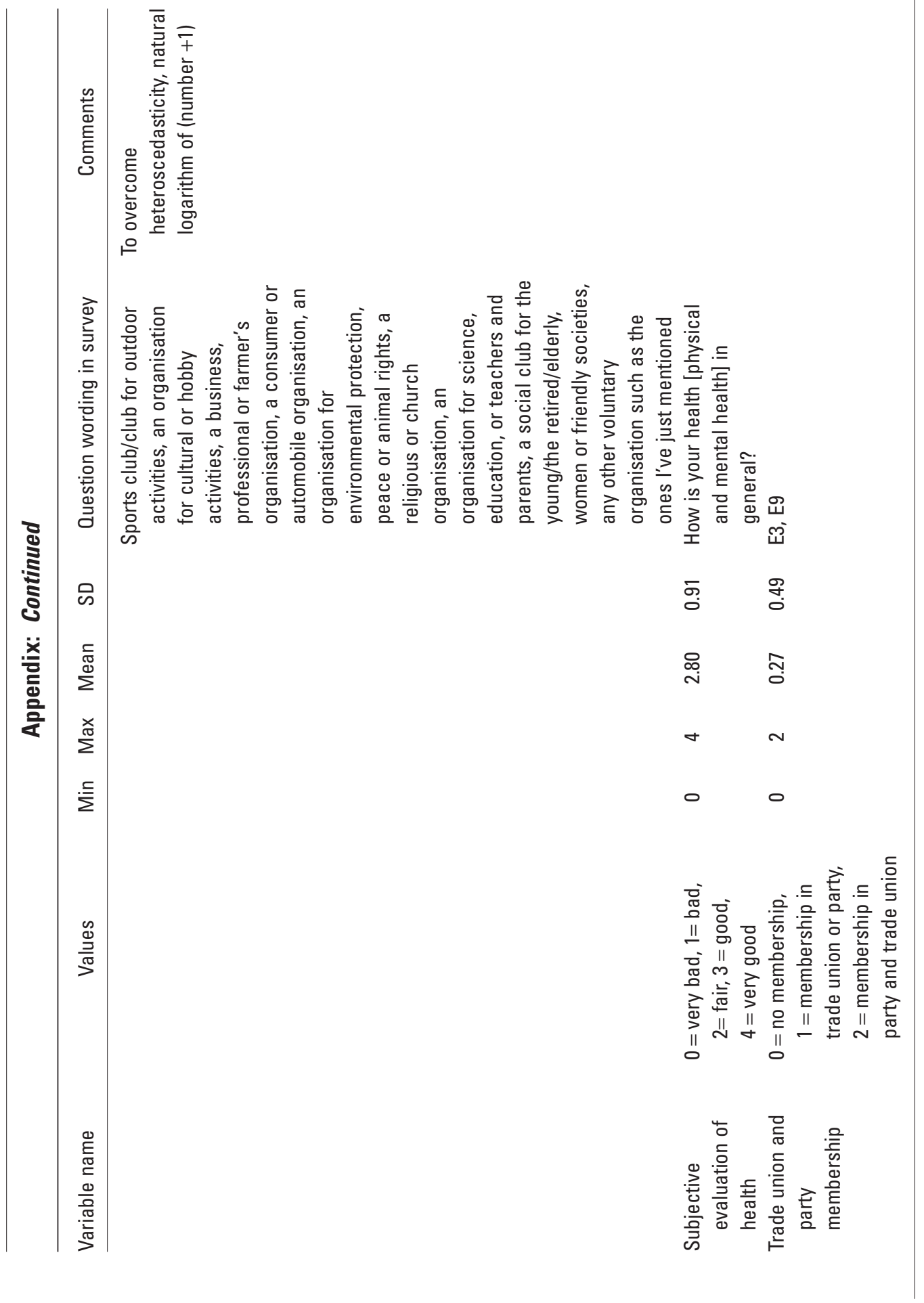




\section{Notes}

The original data set is the European Social Survey Round 1, version 5. It can be freely downloaded at http://www.europeansocialsurvey.org. My own coded dataset and command files can be downloaded from my personal homepage at http://www.achimgoerres.de. I would like to thank Michael Bruter, Rune Dahl Fitjar, Pierre Hausemer, Simon Hix, Simona Milio, Gwen Sasse, David Soskice and Joachim H. Wehner and two anonymous referees for their comments on earlier drafts of this article. Earlier versions of this article were presented at the annual conference of the Political Studies Association in Leeds in April 2005 and the bi-annual conference of the European Consortium for Political Research in Budapest in September 2005. I would like to thank the Economic and Social Research Council, the Ralph Miliband programme and the Government Department at the LSE for their financial support.

1. Similarities include a strong emphasis on chronological age as a social marker, a linear (rather than cyclical) perception of the life course from birth to death and an individualistic outlook that permits very different social roles along the life course (Albert and Cattell 1994, 64-65; Wilson 2000, 27).

2. As a consequence, this dimension of individual ageing must be less developed in relatively new democracies such as the post-communist countries, where the learning process for older voters has been embedded in a relatively unstable political environment over the last 20 years. Although voting was common in communist countries, the lack of choice bears no resemblance to voting in the post-communist era. However, the data and research design does not allow us to test this proposition.

3. The increasing tendency of older people to conform to norms in voting behaviour has been observed in Blais $(2000,112)$, where the author states that older people are more inclined to think 'in terms of morality and principle'.

4. Cialdini and Trost (1991) make a distinction between a descriptive norm versus an injunctive norm.

5. This dimension of individual ageing should be visible in all consolidated democracies. An older person in a post-communist country is as likely to be exposed to a greater subjective norm to vote (relative to a younger fellow citizen) as someone in an established democracy. Turnout in consolidated new democracies is not lower than in older democracies. Rose and Munro (2003, ch. 4) show that voting participation is comparable to the west in post-communist countries, despite distrust of political institutions and parties.

6. Nie et al. were the first to suggest such an approach to study age and political participation (Nie et al. 1974, 322): 'The nature and timing of major political events vary from country to country. If we find uniformity in the relationship between political activities and age across these nations [Austria, Britain, India, Nigeria, United States], it is unlikely that such uniformity was produced by uniform generational experiences. It is far more likely that such uniformity reflects the uniform impact of aging'.

7. Technically, we do not need to make the life cycle and cohort categorisation because these independent variables mainly serve as control variables to isolate the individual ageing effect. However, these effects are well researched, and the conceptual categorisation is a helpful tool to discuss the political implications such as the fact that life-cycle effects are more stable than cohort effects.

8. Each one of them correlates with age at least 0.10 in two or more countries. The table of correlations is obtainable from the author.

9. One might question the validity of subjective self-evaluation of one's own health, but this evaluation is, first of all, highly correlated with objective health measures and secondly this self-image is a powerful force by itself (see Bazargan et al. 1991, 183-184).

10. There is also evidence at the ecological level that districts with high levels of residential mobility have lower turnout (Gimpel et al. 2004).

11. Nagler (1991) has correctly raised the problems of artificial interaction effects in logistic regression that are due to the S-shaped probability curve. As a simple remedy to test whether the observed interaction effect between age and education is an artefact or real, I ran the same regression for all seven educational groups separately. The changes in the coefficient of the age dummies correspond to what we would expect from the interaction effect. Therefore, this interaction term is not an artefact of the regression technique.

12. Sample size for each country is still above 1,000 .

13. Vote to voting age population ratio.

14. Sampling error alone can explain much variation just between different samples of the same population and does not need to hint at systematic differences between the country groups.

15. In general, we can expect bias in terms of respondents over-reporting their sense of duty because it is a socially desirable trait. It is reasonable to assume, however, that this bias does not differ between age groups (Verba et al. 1995, appendix B). 


\section{Bibliography}

Aarts, H., Verplanken, B. and Van Knippenberg, A. (1998) 'Predicting behavior from actions in the past: Repeated decision making or a matter of habit?', Journal of Applied Social Psychology, 28:15, 1355-1374.

Ajzen, I. (1991) 'The theory of planned behavior', Organizational Behavior and Human Decision Processes, 50, $179-211$.

Ajzen, I. (2002) 'Residual effects of past on later behavior: Habituation and reasoned action perspectives', Personality and Social Psychology Review, 6:2, 107-122.

Ajzen, I. and Fishbein, M. (1980) Understanding Attitudes and Predicting Social Behavior (New Jersey: Prentice-Hall).

Albert, S. M. and Cattell, M. G. (1994) Old Age in Global Perspective. Cross-cultural and Cross-national Views (New York: G. K. Hall \& Co.).

Alwin, D. F., Cohen, R. L. and Newcomb, T. M. (1991) Political Attitudes over the Life Span: The Bennington Women after Fifty Years (Madison, WI: University of Wisconsin Press).

Bazargan, M., Kang, T. S. and Bazargan, S. (1991) 'A multivariate comparison of elderly African Americans and Caucasians voting behavior: How do social, health, psychological and political variables effect their voting?', International Journal of Aging and Human Development, 32, 181-198.

Becker, R. (2002) 'Wahlbeteiligung im Lebensverlauf. A-P-K-Analysen für die Bundesrepublik Deutschland in der Zeit von 1953 bis 1987', Kölner Zeitschrift für Soziologie und Sozialpsychologie, 54:2, 246-263.

Blais, A. (2000) To Vote or Not to Vote. The Merits and Limits of Rational Choice Theory (Pittsburgh: University of Pittsburgh Press).

Blais, A., Gidengil, E., Nevitte, N. and Nadeau, R. (2004) 'Where does turnout decline come from?', European Journal of Political Research, 43, 221-236.

Butler, D. and Stokes, D. (1983) Political Change in Britain. The Evolution of Electoral Choice (London/ Basingstoke: Macmillan).

Campbell, A. L. (2003) How Policies Make Citizens (Princeton/Oxford: Princeton University Press).

Cialdini, R. B. and Trost, M. R. (1991) 'Social influence: Social norms, conformity, and compliance', in D. T. Gilbert, S. T. Fiske and G. Lindzey (eds), The Handbook of Social Psychology (Boston: McGraw-Hill), 151-191.

Clarke, H. D., Sanders, D., Stewart, M. C. and Whiteley, P. F. (2004) Political Choice in Britain (Oxford: Oxford University Press).

Converse, P. E. (1976) The Dynamics of Party Support: Cohort-analyzing Party Identification (Beverly Hills: Sage).

Cumming, E. and Henry, W. E. (1961) Growing Old: The Process of Disengagement (New York: Basic Books).

Dalton, R. J. (2002) Citizen Politics: Public Opinion and Political Parties in Advanced Western Democracies (New York/London: Chatham House).

Dawson, R. E. and Prewitt, K. (1968) Political Socialization: An Analytic Study (Boston: Little Brown).

Dowding, K. (2005) 'Is it rational to vote? Five types of answer and a suggestion', British Journal of Politics O International Relations, 7:3, 442-459.

Fishbein, M. and Ajzen, I. (1975) Belief, Attitude, Intention and Behavior: An Introduction to Theory and Research (Reading, MA: Addison-Wesley).

Franklin, M. N. (1996) 'Electoral participation', in L. LeDuc, R. G. Niemi and P. Norris (eds), Comparing Democracies. Elections and Voting in Global Perspective (Thousand Oaks/London/New Delhi: Sage), 216235.

Franklin, M. N. (2004) Voter Turnout and the Dynamics of Electoral Competition in Established Democracies (Cambridge: Cambridge University Press).

Franklin, M. N., van der Eijk, C. and Oppenhuis, E. (1996) 'The institutional context: Turnout', in C. van der Eijk and M. N. Franklin (eds), Choosing Europe? The European Electorate and National Politics in the Face of Union (Ann Arbor, MI: The University of Michigan Press), 306-331.

Fuchs, D. and Klingemann, H.-D. (eds) (1995) Citizens and the State (Oxford: Oxford University Press).

Gehring, U. W. and Wagner, M. (1999) 'Wahlbeteiligung im hohen und sehr hohen Alter', kölner Zeitschrift für Soziologie und Sozialpsychologie, 51:4, 681-705. 
Gerber, A. S., Green, D. P. and Shachar, R. (2003) 'Voting may be habit-forming: Evidence from a randomized field experiment', American Journal of Political Science, 47:3, 540-550.

Gergen, K. J. and Back, K. W. (1966) 'Communication in the interview and the disengaged respondent', Public Opinion Quarterly, 30, 385-398.

Gimpel, J. G., Morris, I. L. and Armstrong, D. R. (2004) 'Turnout and local age distribution: Examining political participation across space and time', Political Geography, 23, 71-95.

Glenn, N. D. (1969) 'Aging, disengagement, and opinionation', Public Opinion Quarterly, 33:1, 17-33.

Glenn, N. D. (1976) 'Cohort analysts' futile quest: Statistical attempts to separate age, period and cohort effects: Response', American Sociological Review, 41:5, 900-905.

Glenn, N. D. and Grimes, M. (1968) 'Aging, voting, and political interest', American Sociological Review, 35 , $563-575$.

Henn, M., Weinstein, M. and Wring, D. (2002) 'A generation apart? Youth and political participation in britain', British Journal of Politics $\theta$ International Relations, 4:2, 167-192.

Hyman, H. H. (1959) Political Socialization. A Study in the Psychology of Political Behaviour (Glencoe: The Free Press).

IDEA (2005) Voter Turnout since 1945. A Global Report 2002. Available online at: http://www.idea.int/ publications/vt/upload/VT_screenopt_2002.pdf (accessed 10 July 2005).

Knoke, D. (1990) 'Networks of political action: Toward theory construction', Social Forces, 68, 1041-1063.

Lau, R. R. (2003) 'Models of decision-making', in D. O. Sears, L. Huddy and R. Jervis (eds), Oxford Handbook of Political Psychology (Oxford: Oxford University Press), 19-59.

Leighly, J. E. (1995) 'Attitudes, opportunities and incentives: A field essay on political participation', Political Research Quarterly, 48:1, 181-209.

Miller, W. E. and Shanks, J. M. (1996) The New American Voter (Cambridge, MA/London: Harvard University Press).

Nagler, J. (1991) 'The effect of registration laws and education on US voter turnout', American Political Science Review, 85:4, 1393-1405.

Nie, N. H., Verba, S. and Kim, J.-O. (1974) 'Political participation and the life cycle', Comparative Politics, 6:3, 319-340

Rollenhagen, R. E. (1982) Testing Disengagement Theory as an Explanation of Political Inactivity (Department of Political Science, Michigan State University, Ph.D. thesis).

Rose, R and Munro, N. (2003) Elections and Parties in New European Democracies (Washington DC: CQ Press).

Rosenstone, S. J. and Hansen, J. M. (1993) Mobilization, Participation, and Democracy in America (New York: Macmillan)

Russell, A. T., Johnston, R. J. and Pattie, C. J. (1992) 'Thatcher's children: Exploring the links between age and political attitudes', Political Studies, 40, 742-756.

Sears, D. O. and Levy, S. (2003) 'Childhood and adult political development', in D. O. Sears, L. Huddy and R. Jervis (eds), Oxford Handbook of Political Psychology (Oxford: Oxford University Press), 60-109.

Snijders, T. A. B. and Bosker, R. J. (1999) Multilevel Analysis. An Introduction to Basic and Advanced Multilevel Modeling (London: Sage).

Tilley, J. R. (2003) 'Party identification in Britain: Does length of time in the electorate affect strength of partisanship?', British Journal of Political Science, 33, 332-344.

Verba, S., Schlozman, K. L. and Brady, H. E. (1995) Voice and Equality: Civic Voluntarism in American Politics (Cambridge: Harvard University Press).

Widfeldt, A. (1995) 'Party membership and party representativeness', in D. Fuchs and H.-D. Klingemann (eds), Citizens and the State (Oxford: Oxford University Press), 134-182.

Wilson, G. (2000) Understanding Old Age. Critical and Global Perspectives (London/Thousand Oaks/New Delhi: Sage).

Wolfinger, R. E. and Rosenstone, S. J. (1980) Who Votes? (New Haven: Yale University Press). 